\title{
POLYMYXIN SENSITIVITY OF CANDIDA TROPICALIS
}

\author{
M. W. N. Nicholls \\ Departments of Microbiology, University College Hospital and Whittington Hospital, London
}

THE treatment of candida infections in man by the polyene antibiotics is well established; for systemic infections, particularly with septicaemia, amphotericin B is the most widely used and successful (Drouhet, 1963). There is, however, evidence of renal toxicity associated with its use (Utz, 1964) and permanent histological changes have been recorded (Sanford, Rasch and Stonehill, 1962). The possibility that a less toxic antibiotic might be of value for systemic use seemed worthy of investigation.

The observation by Dr A. F. Mohun that a strain of Candida tropicalis from a catheter specimen of urine was sensitive to colistin sulphomethate led to the successful treatment of the patient with that drug. This provoked the questions of what proportion of clinically derived yeasts were sensitive to the polymyxins, what factors influence the in-vitro sensitivity tests, and what is the mode of action of polymyxins on yeasts. The present paper is a report of the case and of studies of these problems.

No published reports of the sensitivity of $C$. tropicalis to the polymyxins, nor of its clinical treatment with one of these drugs have been found.

\section{MATERIALS AND METHODS}

Yeasts. Unidentified yeasts, randomly selected without distinction as to site of origin, were obtained from specimens sent to the laboratories at the Whittington Hospital (WH) and University College Hospital (UCH). Isolation on Sabouraud's medium containing chloramphenicol (at WH), or penicillin and streptomycin (at $\mathrm{UCH}$ ) was followed by purification on the same medium containing $100 \mu \mathrm{g}$ gentamicin per $\mathrm{ml}$ and storage on Dorset's egg medium from the Southern Group Laboratory (SGL). Strains suspected of being C. tropicalis because they showed sensitivity to colistin were identified by their characteristic colonial and mycelial growth on corn-meal agar, and by their fermentation, with gas production, of glucose, maltose, and sucrose and by the assimilation of glucose, galactose, maltose, and sucrose.

Identified yeasts from the Mycological Reference Laboratory were kindly supplied by Dr I. G. Murray, to whom they had been sent from various parts of Great Britain. Dr Murray also provided the reference strain IGM7.

The antibiotic. Polymyxin $\mathrm{E}$ consists of two fractions, $\mathrm{E}_{1}$ and $\mathrm{E}_{2}$, which are identical with colistin A and colistin B fractions of the sulphomethate preparation (Suzuki et al., 1965). Sulphomethate derivatives have reduced antibacterial activity and reduced toxicity, in each respect being about one-third as active as the parent peptide ( $\mathrm{O}^{\prime} \mathrm{Grady}$ and Pennington, 1967). Urinary excretion of the sulphomethate preparations is greater, however, and for this reason colistin sulphomethate was used for treating the patient. This was also the antibiotic used in liquid and solid media for determining the sensitivity of the clinical isolates; it was added to solid media immediately before plate pouring because of the possibility of liberating a more active compound during heating.

Received 15 Nov. 1969; accepted 20 Jan. 1970.

J. MED. MICROBIOL.-VOL. 3 (1970) 
For studies on the action of the polymyxins on the yeast cell-membrane by a spectrophotometric method, the more stable and chemically pure peptides polymyxin $\mathrm{E}$ sulphate and polymyxin B sulphate (Burroughs Wellcome) were used. Polymyxin E was also directly compared with the colistin sulphomethate derivative for fungicidal activity on ten known sensitive strains.

Media for sensitivity tests. The basic media were different in the two laboratories. Infusion agar (SGL) or Diagnostic Sensitivity-test Agar (Oxoid) were used for tests on solid medium, sometimes with the addition of 1 per cent. glucose. For tests in liquid medium, Hartley's digest broth (SGL) or beef infusion nutrient broth (UCH, home-made) were used. No differences were found between the results obtained in these media.

Antibiotic assay and determination of minimum inhibitory concentrations. Assays of the antibiotics in the patient's blood and urine were performed in glucose broth in a series of tubes in which the ratio of dilutions in adjacent tubes was $1: \sqrt{2}$ (i.e., 1.4). Each tube was inoculated with a stock strain of Klebsiella aerogenes (K3) of known sensitivity. For assay of antibiotic in serum, dilutions were made in serum. The antibiotic used in the control series was the sodium salt of colistin sulphomethate. A similar series of dilutions was used for determination of the minimum inhibitory concentration (MIC) of antibiotics for yeasts.

Screening for colistin sensitivity. At first, tube tests were used but later, to screen large numbers of yeasts, a multiple-loop inoculator-made by adapting a phage-typing machinewas used to inoculate agar plates containing various concentrations of antibiotic. Loops of 4-mm diameter were charged with part of an overnight culture from a single colony in glucose broth, and plates were inoculated from those of the lowest to those of the highest antibiotic content. It was thus possible to screen up to 24 isolates simultaneously against a range of antibiotic concentrations in agar; all plates were duplicated, and sensitive and resistant control strains were included in each run. Antibiotic-free media and Sabouraud's medium were included to confirm viability of the inocula.

Glucose effect. MIC determinations were performed in liquid media containing a range of glucose concentrations and a fixed inoculum, and on solid media with ranges of glucose concentrations and of inoculum. The size of inocula was controlled by surface-viable counts (Miles, Misra and Irwin, 1938) on Sabouraud's medium.

Fungicidal effect. The killing power of colistin sulphomethate $(2000 \mu \mathrm{g}$ per $\mathrm{ml})$ against a sensitive strain of $C$. tropicalis (IGM7) in glucose broth at $37^{\circ} \mathrm{C}$ was measured by explanting at intervals from the mixture and counting viable cells on Sabouraud's medium by Miles and Misra's method (Miles, Misra and Irwin).

Site of polymyxin activity. To investigate the action of polymyxin on the yeast cellmembrane the method described by Newton (1953) was used. This method measures the liberated intracellular material by the increase in optical density of a suspending solution, which is read in a spectrophotometer at a wavelength of $260 \mathrm{~nm}$. C. tropicalis was washed from several Sabouraud plates and the suspension was washed thrice in sterile distilled water. The packed-cell volume was measured in a microhaematocrit. Known volumes of the suspension were added to polymyxin dilutions in water. Polymyxin E and polymyxin B were tested by this method. After incubation at $37^{\circ} \mathrm{C}$ or at $22^{\circ} \mathrm{C}$ and centrifugation at $3000 \mathrm{r}$.p.m. for $20 \mathrm{~min}$. the supernatant fluid was carefully removed to $10-\mathrm{mm}$ silica cuvettes and the optical density was read on a "Unicam " SP 500 spectrophotometer. Three or four different polymyxin concentrations were tested simultaneously. For each, two tubes were prepared: one received yeast suspension whilst the other, receiving no yeast but otherwise treated in the same way, gave a blank reading. A simple yeast suspension without polymyxin and treated identically was used as a control to give the value for the leakage of intracellular material that is inherent in the method.

\section{CASE REPORT}

The patient, Mrs M. W., aged 59, had a 13-yr history of slowly progressive multiple sclerosis. After the death of her husband she was admitted to the Whittington Hospital with abrupt deterioration of her walking, balance, and memory. On admission she had 
symptoms of a urinary-tract infection, and urinary incontinence, which was thought to be of neurological origin. Escherichia coli was isolated from the urine in numbers greater than $10^{5}$ per $\mathrm{ml}$, and treatment was started with ampicillin, to which the isolate was sensitive; a catheter was left in situ.

Two days after the end of this treatment, microscopy of a catheter specimen of urine revealed many pus cells and yeasts; cultures yielded more than $10^{5}$ yeasts per $\mathrm{ml}$ of urine. Routine disk-diffusion sensitivity tests showed the yeasts-later identified as C. tropicalisto be sensitive to colistin sulphomethate. During the next $24 \mathrm{hr}$ the catheter was changed, two blood cultures were taken, and another specimen of urine was examined with results identical to those of the first. Both blood cultures remained sterile during incubation for $2 \mathrm{wk}$. The MIC of colistin sulphomethate sodium for the yeast was $125 \mu \mathrm{g}$ per ml. As this was below the concentration attainable in the urine it was decided to start treatment with this antibiotic at a dose of $4 \mathrm{mg}$ per $\mathrm{kg}$ per $24 \mathrm{hr}$ ( 1.0 mega-units, 8 -hourly) by intramuscular injection.

Immediately before the first three mid-day injections the urinary concentrations of colistin were 180,144 , and $346 \mu \mathrm{g}$ per ml respectively, all above the MIC of the isolate, which showed no decrease of sensitivity during the period of treatment. The corresponding serum concentrations were $5 \cdot 6,23$, and $44 \mu \mathrm{g}$ per $\mathrm{ml}$ respectively. Surface-spread counts of the yeasts from the urine were performed daily and were diminishing when a hypersensitivitytype rash necessitated stopping the antibiotic after a total dose of only $960 \mathrm{mg}$. Culture of urine on the 6th and 14th days after the start of treatment yielded no yeasts. Serum taken on the 3rd and 14th days contained no candida precipitins.

\section{RESULTS \\ Identity of colistin-sensitive yeasts}

Four hundred isolates-200 from each hospital - were obtained from clinical material; these were screened for sensitivity to colistin sulphomethate on solid and in liquid media. At first, strains that failed to grow in broth containing $250 \mu \mathrm{g}$ per $\mathrm{ml}$ or on nutrient agar containing $150 \mu \mathrm{g}$ per $\mathrm{ml}$ were set aside for identification. It became apparent that these concentrations could be reduced to $150 \mu \mathrm{g}$ per $\mathrm{ml}$ for broth and to $100 \mu \mathrm{g}$ per $\mathrm{ml}$ for nutrient agar; strains sensitive to these concentrations proved to be C. tropicalis. Minimal inhibitory concentrations were not determined for the sensitive isolates. The most clear-cut results were obtained with the multiple-inoculum technique for which it was found possible to reduce the number of plates to four: one each of Sensitivity-Test Agar containing $500 \mu \mathrm{g}$ per $\mathrm{ml}$ and $100 \mu \mathrm{g}$ per $\mathrm{ml}$ of colistin sulphomethate, one with no colistin, and one Sabouraud plate with no colistin. Growth on the last two indicated adequate inoculum, whilst failure to grow on both colistin-containing plates was characteristic of $C$. tropicalis. It was noted that $C$. albicans, included in each run as a control, grew in the presence of the higher concentration of antibiotic. Of the 400 strains tested, 25 (6.2 per cent.) were sensitive to the antibiotic; $22(5.5$ per cent.) proved to be $C$. tropicalis, 2 were $C$. pseudotropicalis, and 1 was $C$. krusei. The percentage of sensitive yeasts was almost the same in both hospitals.

\section{Colistin sensitivity of various yeasts}

One hundred and twelve identified yeasts from the Mycological Reference Laboratory were tested on solid and in liquid media. The results (table I) 
showed that all 12 strains of $C$. tropicalis were sensitive to the screening concentrations of colistin sulphomethate and that one strain each of $C$. pseudotropicalis and C. krusei was also sensitive. Of the remaining strains, seven of

TABLE I

Sensitivity of identified yeasts to colistin sulphomethate*

\begin{tabular}{|c|c|c|}
\hline \multirow{2}{*}{ Species } & \multicolumn{2}{|c|}{ Number of strains: } \\
\hline & tested & sensitive \\
\hline $\begin{array}{l}\text { Candida albicans } \\
\text { C. parapsilosis } \\
\text { C. tropicalis } \\
\text { C. pseudotropicalis } \\
\text { C. krusei } \\
\text { Torulopsis spp. } \\
\text { Crypt. nooformans } \\
\text { Rhodotorula spp. }\end{array}$ & $\begin{array}{r}45 \\
29 \\
12 \\
2 \\
3 \\
15 \\
3 \\
3\end{array}$ & $\begin{array}{c}0 \\
0 \\
12 \\
1 \\
1 \\
0 \dagger \\
\text { Inadequate growth } \\
0\end{array}$ \\
\hline
\end{tabular}

* $150 \mu \mathrm{g}$ per $\mathrm{ml}$ in liquid medium or $100 \mu \mathrm{g}$ per $\mathrm{ml}$ on solid medium.

$\dagger$ Seven failed to grow.

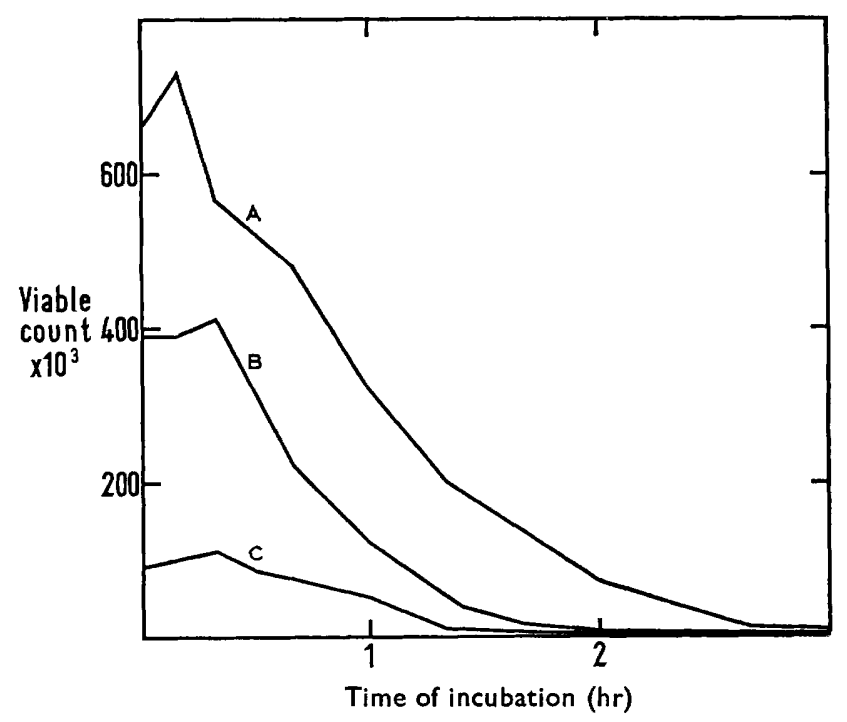

FIGURE.-Fungicidal action of colistin sulphomethate sodium $2000 \mu \mathrm{g}$ per $\mathrm{ml}$ on C. tropicalis during incubation at $37^{\circ} \mathrm{C}$. A, B and C: experiments with inocula of different sizes.

Torulopsis failed to grow on the control plates, and the remaining eight were not sensitive. None of the three strains of Cryptococcus neoformans gave satisfactory growth on the control plates. Duplicate tests at $26^{\circ} \mathrm{C}$ were not performed. 


\section{Demonstration of fungicidal activity}

The figure illustrates the killing of the reference strain of $C$. tropicalis (IGM7) by $2000 \mu \mathrm{g}$ of colistin sulphomethate per $\mathrm{ml}$. With large, intermediate,

TABLE II

Effects of glucose concentration and inoculum size on minimum inhibitory concentration (MIC) of colistin sulphomethate for C. tropicalis

\begin{tabular}{|c|c|c|c|c|c|c|c|}
\hline \multirow{2}{*}{$\begin{array}{l}\text { Culture } \\
\text { medium }\end{array}$} & \multirow{2}{*}{$\begin{array}{l}\text { Inoculum: } \\
\text { number of } \\
\text { viable cells }\end{array}$} & \multicolumn{6}{|c|}{$\begin{array}{l}\text { MIC }(\mu \mathrm{g} \text { per } \mathrm{ml}) \text { when } \\
\text { glucose concentration per cent. was }\end{array}$} \\
\hline & & 4 & 2 & 1 & $0 \cdot 4$ & 0.04 & 0 \\
\hline Nutrient broth & $2 \cdot 3 \times 10^{3}$ & 90 & $\ldots$ & $\ldots$ & 90 & 64 & 64 \\
\hline Nutrient agar & $\begin{array}{l}1.45 \times 10^{6} \\
1.45 \times 10^{5} \\
1.45 \times 10^{4} \\
1.45 \times 10^{3}\end{array}$ & $\begin{array}{l}\cdots \\
\cdots \\
\cdots \\
\cdots\end{array}$ & $\begin{array}{r}175 \\
87 \\
87 \\
87\end{array}$ & $\begin{array}{r}125 \\
87 \\
87 \\
87\end{array}$ & $\begin{array}{r}125 \\
87 \\
87 \\
62\end{array}$ & $\begin{array}{l}\cdots \\
\cdots \\
\cdots \\
\cdots\end{array}$ & $\begin{array}{l}\ldots \\
\cdots \\
\cdots \\
\cdots\end{array}$ \\
\hline
\end{tabular}

and small inocula of yeast the number of viable cells increased for the first 10-20 min., then fell by 90 per cent. or more during the next $2 \mathrm{hr}$. All incubation mixtures were sterile at $22 \mathrm{hr}$.

TABLE III

Comparison of the activity of polymyxin $E$ and colistin sulphomethate sodium against $C$. tropicalis

\begin{tabular}{|c|c|c|}
\hline \multirow{2}{*}{ Strain } & \multicolumn{2}{|c|}{ Minimum inhibitory concentration ( $\mu \mathrm{g}$ per $\mathrm{ml})$ of } \\
\hline & polymyxin $\mathrm{E}$ & colistin sulphomethate \\
\hline $\begin{array}{r}1 \\
2 \\
3 \\
4 \\
5 \\
6 \\
7 \\
8 \\
9 \\
10\end{array}$ & $\begin{array}{l}40 \\
75 \\
30 \\
40 \\
50 \\
50 \\
40 \\
30 \\
40 \\
40\end{array}$ & $\begin{array}{l}150 \\
150 \\
125 \\
150 \\
175 \\
150 \\
125 \\
125 \\
150 \\
150\end{array}$ \\
\hline $\begin{array}{l}\text { Mean } \\
\text { Range : }\end{array}$ & $\begin{array}{c}43 \cdot 5 \\
30 \cdot 0-75 \cdot 0\end{array}$ & $\begin{array}{c}145 \cdot 0 \\
125 \cdot 0-175 \cdot 0\end{array}$ \\
\hline
\end{tabular}

Effect of glucose and of inoculum-size on sensitivity

Table II first shows the effect of glucose concentration in liquid medium on the sensitivity of $C$. tropicalis strain W3U from the urine of the patient already described. A 100 -fold increase in the glucose content led to a rise of 
the MIC by $\sqrt{ } 2$-fold-i.e., $\times 1 \cdot 4$-or half a tube in the usual doubling-dilution series. Table II also shows the MIC for different inocula on nutrient agar with three different glucose concentrations. A 1000 -fold increase in inoculum size caused a $\sqrt{ } 2$ - or 2-fold increase in MIC.

TABLE IV

Optical density of supernatant fluid after incubation of $C$. tropicalis with polymyxins at $37^{\circ} \mathrm{C}$ for $20 \mathrm{~min}$.

\begin{tabular}{|c|c|c|c|}
\hline \multicolumn{4}{|c|}{ Polymyxin E } \\
\hline \multirow{2}{*}{$\begin{array}{l}\text { Amount of } \\
\text { antibiotic } \\
(\mu \mathrm{g} \text { per } \mathrm{ml})\end{array}$} & \multicolumn{3}{|c|}{$\begin{array}{c}\text { Increase in scale reading after incubation with } \\
\text { antibiotic of aqueous yeast suspension of } \\
\text { concentration }(v / v)\end{array}$} \\
\hline & \multicolumn{2}{|c|}{1 per cent. } & 0.75 per cent. \\
\hline $\begin{array}{r}0 \\
10 \\
20 \\
100 \\
150 \\
200\end{array}$ & \multicolumn{2}{|l|}{$\begin{array}{l}0.08 \\
0.165 \\
0.325 \\
0.780 \\
0.80 \\
\ldots\end{array}$} & $\begin{array}{c}0.02 \\
\ldots \\
0.027 \\
\ldots \\
0.63 \\
0.67\end{array}$ \\
\hline \multicolumn{4}{|c|}{ Polymyxin B } \\
\hline \multirow{2}{*}{$\begin{array}{l}\text { Amount of } \\
\text { antibiotic } \\
(\mu \mathrm{g} \text { per ml })\end{array}$} & \multicolumn{3}{|c|}{$\begin{array}{c}\text { Increase in scale reading after incubation with } \\
\text { antibiotic of aqueous yeast suspension of } \\
\text { concentration }(\mathrm{v} / \mathrm{v})\end{array}$} \\
\hline & 1.8 per cent. & 1.6 per cent. & $1 \cdot 2$ per cent. \\
\hline $\begin{array}{r}0 \\
10 \\
20 \\
30 \\
50 \\
100\end{array}$ & $\begin{array}{c}0.10 \\
0.75 \\
\dddot{70} \\
1.40 \\
1.80\end{array}$ & $\begin{array}{c}0.14 \\
0.37 \\
\ldots \\
0.96 \\
1.16 \\
\ldots\end{array}$ & $\begin{array}{c}0.05 \\
0.60 \\
\ldots \\
0.80 \\
0.85 \\
\ldots\end{array}$ \\
\hline
\end{tabular}

Comparison of polymyxin $E$ and colistin sulphomethate

Sensitive strains of $C$. tropicalis were tested against both preparations simultaneously, with a different incremental series of concentrations for each drug. Table III shows the greater activity of polymyxin E (about three-fold); this is consistent with a previous assessment of bactericidal activities (Barnett, Bushby and Wilkinson, 1964).

\section{Cell-membrane activity}

The optical density of the supernatant fluid was measured after incubation of aqueous suspensions of $C$. tropicalis with polymyxin $\mathrm{E}$ and with polymyxin $\mathrm{B}$. 
The reading after incubation without antibiotic indicated the background loss of intracellular material that was to be expected, and was assumed to remain constant for any one experiment. Increase in optical density above this indicated the amount of intracellular substance that became extracellular as a result of antibiotic action.

The results (table IV) show that the optical density at $260 \mathrm{~nm}$ wavelength increased as the polymyxin concentration increased in the incubation mixture. Yeast-cell suspensions of different concentrations were used in each experiment, and it is therefore not valid to compare horizontal values for a given polymyxin concentration. A smaller rise in the optical density was found when C. tropicalis and polymyxin $\mathrm{E}$ were incubated at $22^{\circ} \mathrm{C}$ for 30 and for $22 \mathrm{~min}$.

\section{Discussion}

Candida tropicalis is a well-documented opportunist pathogen of man. It was responsible for 38 per cent. of 92 cases of vaginal candidosis and 44 per cent. of 18 cases of oral thrush (Hurley, 1966), and in each of these series was the second most frequently isolated Candida. In disseminated candidosis in children and in adults, $C$. tropicalis was again second in frequency of isolation to C. albicans (Winner and Hurley, 1964). As judged by mouse pathogenicity (Hurley) there is no difference between $C$. albicans and $C$. tropicalis if equal inocula are used; it is therefore not surprising to find $C$. tropicalis playing a pathogenic role in the case described here.

The pathogenicity of Candida species is closely associated with predisposing illness such as diabetes and malignancy, and with the administration of steroids, broad-spectrum antibiotics, and immunosuppressive agents. Reports of generalised Candida infections after surgical operations, especially on the heart (Sanger et al., 1962), are becoming common; in treated cases of leukaemia, septicaemia with Candida species accounts for an increasing number of deaths (Hersh et al., 1965). The increasing use of cytotoxic and immunosuppressive drugs can be expected to lead to an increasing number of severe and generalised yeast infections. In Candida septicaemia, $C$. tropicalis forms a remarkably high proportion of the isolates. Utz (1966) in a series of 43 such cases found 12 of the isolates to be C. tropicalis. Rosner (1966) recorded the isolation of C. tropicalis protoplasts from eight out of nine osmotically stabilised blood cultures in a patient whose histologically confirmed endocarditis proved fatal. Local lesions, of mucous membranes or skin for example, are not necessarily associated with general disease, nor do they require systemic treatment.

Urinary-tract infection with Candida is an accepted hazard of instrumentation of the lower urinary tract, particularly when the catheter is indwelling or when the patient is a diabetic (Williams, 1967). The case reported here demonstrates another facet of the risks reported by Williams, in whose series of 48 cases all but seven had received a course of a broad-spectrum antibiotic before the yeast infection. When Candida becomes established in the urinary tract, therapy has hitherto been restricted to a suitably soluble polyene antibiotic, usually amphotericin B. It seems, therefore, that when the identity of the 
yeast and its sensitivity to polymyxin are accurately known, this drug is a useful addition to the existing therapeutic agents.

The value of polymyxin depends not only on the sensitivity of the yeast, but also upon the high urinary concentration attained by the drug, particularly the sulphomethate derivatives (Pulaski and Rosenberg, 1949), which reduces the slight risk of nephrotoxicity. This is true also for bacterial infections (Atuk, Mosca and Kunin, 1964). The urinary concentrations attained during the treatment of the patient described here correspond with previous reports (Pulaski and Rosenberg; Barnett et al., 1964) and are well above the MIC of the yeast. Such a margin is of real therapeutic importance in bacterial infection for, at concentrations equal to the MIC, polymyxin is bacteriostatic (Sebek, 1967). There are no reasons to suppose that the fungicidal concentrations are not similarly related.

Sensitivity to polymyxin is a feature of $C$. tropicalis, but is not confined to this species. Of the 25 sensitive strains among yeasts isolated from patients in two hospitals, three were $C$. pseudotropicalis and two were $C$. krusei. The 5.5 per cent. frequency of $C$. tropicalis in this series, in which only polymyxinsensitive cultures were identified as to species, is somewhat lower than the frequency of $C$. tropicalis previously reported in clinical infections. This might be explained if the method had failed to select all strains of the species. However, the testing of the identified yeasts (table I) showed that all C. tropicalis strains were sensitive. Moreover, the figures presented here are not derived from restricted sampling of patients with overt infection, nor from one particular site.

The sensitivity of individual isolates to polymyxin appears to give optimal reflection of in-vivo response if 1 per cent. glucose is added to the sensitivitytest medium. The multiple-inoculation technique, which can be used for any number of isolates up to 24 , gave easily read, consistent, and readily controlled results, provided that inocula were carefully adjusted to be comparable.

The polymyxins contain in their molecules hydrophilic and hydrophobic groups and at neutral $p \mathrm{H}$ are positively charged. They may be classified as surface-active cationic agents, the antibacterial effect of which derives from the disruption of the cell membrane. The antibiotic is adsorbed at anionic sites on the membrane, sensitive cells binding more of the antibiotic than resistant cells (Newton, 1958). This interaction between antibiotic and cell-membrane with consequent alteration in the permeability of the membrane, is superficially similar to that of the polyene antibiotics, which apparently bind to membrane sterols, thereby enhancing the membrane permeability for anions and, to a lesser extent, cations (Andreoli and Monahan, 1968).

Sensitive bacterial cells treated with polymyxin E, unlike resistant cells, have been shown to liberate intracellular material absorbing light at $260 \mathrm{~nm}$. This material corresponds with free purines, pyrimidines, and nucleotides and is considered to be the gross manifestation of alteration in the cell-membrane permeability barrier (Newton, 1953). The present observations, including the diffusion of material absorbing at $260 \mathrm{~nm}$, suggest that polymyxin $\mathrm{E}$ and polymyxin B act on the cell membranes of sensitive yeasts ( $C$. tropicalis) in much 
the same way as on the membranes of sensitive bacteria. The alteration of membrane permeability may not be the only mechanism by which polymyxin exerts a fungicidal effect for, as Latterrade and Macheboeuf (1950) have shown, yeast ribonucleic acid and polymyxin form an insoluble complex in water.

It might be expected that a polyene antibiotic and polymyxin in combination, each acting at a different site on the cell membrane, would offer the possibility of combined therapy with reduction in the dose of the more nephrotoxic member of the combination, although preliminary experiments have not shown synergy between low concentrations of each drug.

The apparently greater susceptibility of one species of Candida to polymyxin is curious; it suggests that the cell-membrane differences within the genus are of greater significance than has hitherto been suspected.

\section{SUMMARY}

Polymyxin B, polymyxin E, and colistin sulphomethate sodium are fungicidal in vitro for Candida tropicalis. Four hundred random isolates of Candida from two hospital laboratories were tested for sensitivity to colistin: 25 $(6 \cdot 2$ per cent.) were sensitive, and 22 of these were $C$. tropicalis. One hundred and twelve isolates of eight species of Candida were screened for sensitivity to colistin and, of the 14 that were sensitive, 12 were $C$. tropicalis.

Polymyxins B and E liberate intracellular material from C. tropicalis, which suggests that the drug acts on the yeast cell-membrane.

Colistin sulphomethate was successfully used to treat a urinary-tract infection with this species of Candida. The potential therapeutic value of polymyxins for $C$. tropicalis infections is discussed.

I wish to record my gratitude to Dr A. F. Mohun, whose initial observation and subsequent encouragement made this work possible, and whose guidance was so readily available to me at the Whittington Hospital. My thanks are also due to: Dr I. G. Murray and Miss C. Philpott of the Mycological Reference Laboratory, for ready co-operation and advice, for supplying identified yeasts, and for identifying other strains; Dr S. R. M. Bushby, of The Wellcome Research Laboratories, who kindly provided pure crystalline polymyxin E; Dr M. G. Ashby for permission to report the clinical details of the patient who was admitted under his care at the Whittington Hospital; and Dr E. Joan Stokes, for her encouragement and help in the preparation of this paper.

\section{REFERENCES}

Andreoli, T. B., ANd Monahan, M. . 1968. J. Gen. Physiol., 52, 300.

Atuk, N. O., Mosca, A., And Kunin, C. 1964. Ann. Intern. Med., 60, 28.

Barnett, Margaret, Bushby, S. R., 1964. Br.J. Pharmac. Chemother, 23, 552. AND WILKINSON, S.

DrouHET, E.

Hersh, E. M., Bodey, G. P., Nies, B. A., and Freireich, E. J.

HURLEY, ROSALINDE

Latterrade, C., And Macheboeuf, M. . J. MED. MICROBIOL.-VOL. 3 (1970)
1963. Antibiot. Chemother. (Basel), 11, 21.

1965. J. Amer. Med. Assoc., 193, 105.

1966. In Symp. on Candida infection, ed. by

H. I. Winner and Rosalinde Hurley,

Edinburgh, pp. 13 et seq.

1950. Annls Inst. Pasteur, Paris, 78, 753.

$2 \mathrm{M}$ 
Miles, A. A., Misra, S. S., ANd Irwin, 1938. J. Hyg., Camb., 38, 732.

J. $O$.

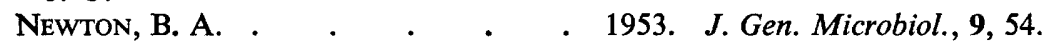

$$
\text { , . . . . . } \quad \text {. 1958. In 8th Symp. Soc. Gen. Microbiol., }
$$

O'Grady, F., and Pennington, J. H. . 1967. Postgrad. Med. J., 43, Suppl., p. 72.

Pulaski, E. J., AND Rosenberg, M. L. . 1949. J. Urol., 62, 564.

ROSNER, R.. . . . . . 1966. J. Bact., 91, 1320.

SANFORD, W. G., Rasch, J. R., and 1962. Ann. Intern. Med., 56, 553.

STONEHILL, R. B.

Sanger, P. W., TAYlor, F. H., Robicsek, 1962. J. Amer. Med. Assoc., 181, 88.

F., Germuth, F., Senterfit, L., AND

MCKINNON, G.

SEBeK, O. K.

- 1967. In Antibiotics I. Mechanism of action, ed. by D. Gottleib and P. D. Shaw, New York, p. 145.

Suzuki, T., Hayashi, K., Funikawa, K., 1965. J. Biochem. (Tokyo), 57, 226. AND TSUKAMOTO, $\mathrm{K}$.

UTZ, J. P.

1964. Ann. Intern. Med., 61, 334.

" . . . . . . 1966. In Symp. on Candida infection, ed. by

Williams, R. E. O. - . $\quad$. 1967. Infections in medical patients. In III H. I. Winner and Rosalinde Hurley, Edinburgh, p. 221.

- Symp. Advanced Medicine, ed. by E. M. Dawson, London, p. 9.

Winner, H. I., AND Hurley, Rosalinde 1964. Candida albicans, London, p. 54. 